\title{
Research on flood destruction forecast of Western Zhejiang rural highway based on GA-BP neural network method
}

\author{
Wang Baofeng ${ }^{1, a}$ \\ ${ }^{1}$ Quzhou University, Quzhou (324000) \\ a909814008@qq.com
}

Keywords: BP neural network; rural highway; GA

Abstract. Using genetic algorithm to optimize BP neural network can solve the problem of slow training speed of BP neural network and easy to fall into local minimum points. GA-BP neural network model for forecasting rural highway flood destruction can realize the effective combination of global optimization and local optimization, greatly improving the learning performance and the convergence of flood destruction forecast model. It is proved that the GA-BP neural network has fast calculation speed, and excellent flood destruction forecast function for rural highway.

\section{Introduction}

The flood destruction is the damage phenomenon and process of various engineering structures and facilities along the highway after suffering storm, flood erosion, water soaked and other water effect [1]. During annual rainy season, Western Zhejiang will face the damage of flood destruction, especially rural highway suffers severe damage. Though using BP neural network to forecast the flood destruction has its superiority, its training speed is slow and it is easy to fall into local minimum points, which restricts the application of the flood destruction forecast. However, the genetic algorithm stars search from one population of the possibly potential solution set of the representative issue, with the ability of global optimization. It can optimize the BP neural network structure, initialize weight number and threshold value, so as to improve the accuracy and stability of BP neural network flood destruction forecast results. This study adopts GA-BP neural network to the constitute flood destruction prediction model, to provide support for the prevention and treatment of flood destruction disaster in Western Zhejiang rural areas.

\section{The Establishment of GA_BP Neural Network Model for Rural Highway Flood Destruction Forecast}

\subsection{BP Neural Network Model}

BP neural network is a multilayer feedforward neural network proposed by Rumelhart in 1985, with high arithmetic speed, high solution efficiency, strong self-learning ability and other advantages, which is widely used in the field of engineering ${ }^{[2-]}$. BP neural network generally includes the input layer, hidden layer and output layer, and the neurons of each layer form complete connection, while neurons in the same layer are not connected the topology structure as shown in Figure 1. BP neural network learning consists of information forward-propagating and error backward- propagating ${ }^{[3]}$. BP neural network has favorable self - learning, self-adaption, self - organizing and strong fault tolerance and nonlinear processing ability, and its application range involves many fields such as expert system, pattern recognition and so on. [4].

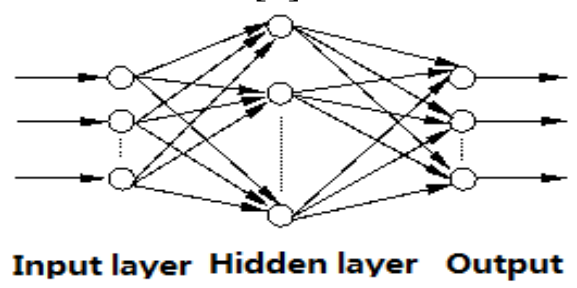

Figure 1 Structure Diagram of BP Neural Network 


\subsection{GA-BP Neural Network Model}

The initial weight value and threshold value of BP neural network are chosen randomly, without optimization, so it is easy to cause slow network convergence speed, and easy to fall into local optimal solution. The genetic algorithm (Genetic Algorithm, referred to as GA) is a kind of parallel random search optimization method, with excellent global optimization ability. Adopt the genetic algorithm to optimize the spatial distribution of BP initial weight value and threshold value; obtain optimal BP neural network initial weight value and threshold value through selection, crossover and mutation and other methods, which can effectively improve the convergence rate of BP neural network, and reduce the possibility that BP algorithm falls into local optimum ${ }^{[5-7]}$. The forecast flow diagram for optimized BP neural network model based on genetic algorithm is shown in Figure 2:

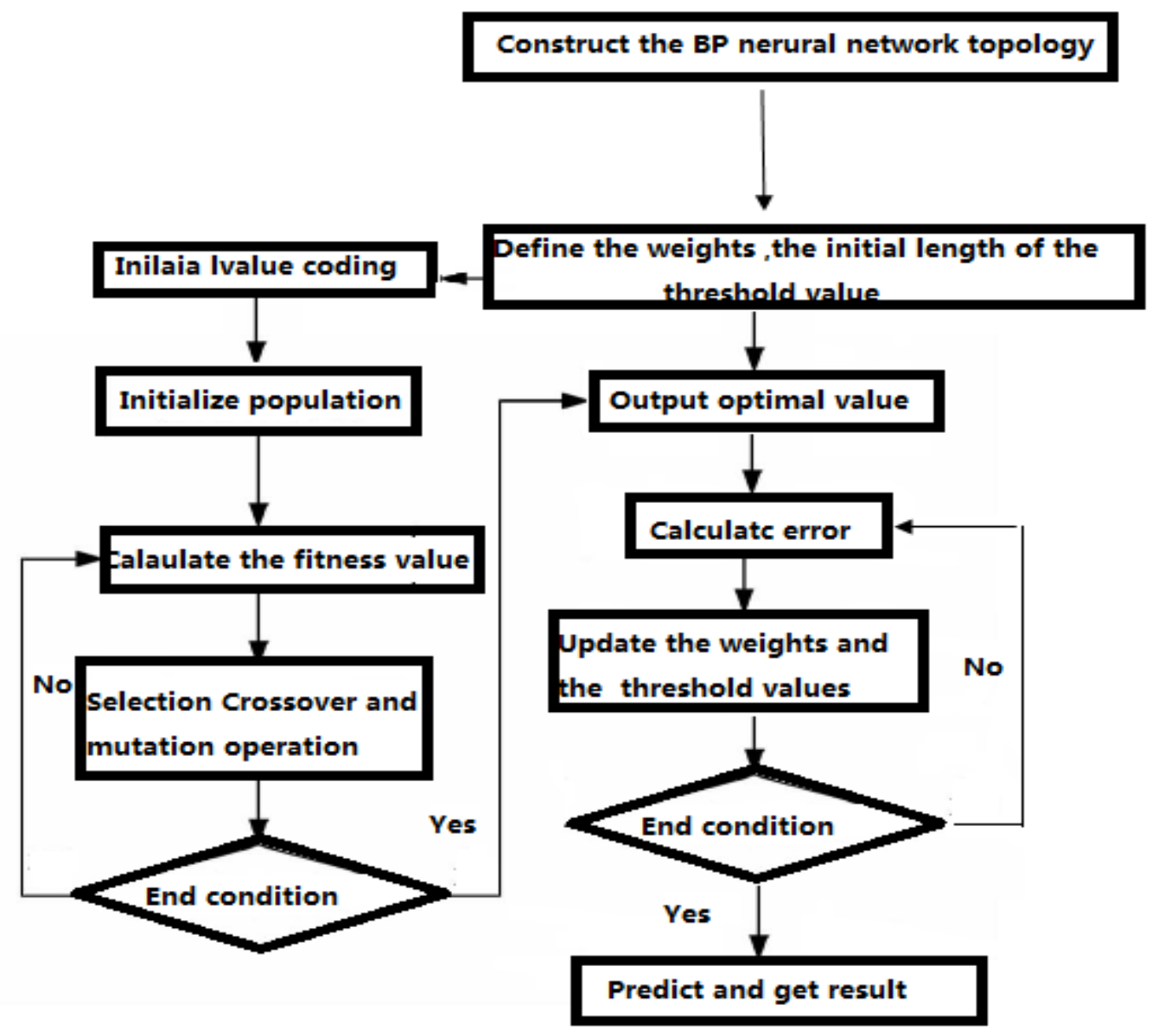

Figure 2 GA-BP neural network model procedure

\section{The Application of GA-BP Neural Network Model for Rural Highway Flood Destruction Forecast}

\subsection{Main Factors Influencing Rural Highway Flood Destruction}

Due to massive data of Zhejiang rural highway flood destruction, some data collection is difficult, such as rainfall. Upon combining the research contents in this chapter, considering the importance and easy access of evaluation index, rainfall capacity will be represented by rainfall type and rainfall duration, meanwhile side slope grade, slope height, cohesive force and friction angle will serve as the model input index. Carry out level quantification according to the specific situation of flood destruction, as shown in Table 1.

Select 40 representative samples data from massive flood destruction date of Zhejiang rural highway as model training samples and testing samples, as shown in table 2 . 
Table 1 Quantification Result of Flood destruction Level

\begin{tabular}{|c|c|c|}
\hline Flood destruction Amount / $\left[\mathrm{g} / \mathrm{m}^{2}\right]$ & Flood destruction Level & Quantification Result \\
\hline$<20$ & Without & 1 \\
\hline $20 \sim 30$ & Slight & 2 \\
\hline $30 \sim 70$ & Medium & 3 \\
\hline $70 \sim 130$ & Serious & 4 \\
\hline$>130$ & Extremely Serious & 5 \\
\hline
\end{tabular}

Table 2 Samples of flood destruction

\begin{tabular}{|c|c|c|c|c|c|c|c|c|}
\hline NO. & Rainfall grade & $\begin{array}{c}\text { Duration } \\
\text { of rainfall } \\
\text { [day] }\end{array}$ & $\begin{array}{l}\text { Slope } \\
\text { angle }^{\circ}\end{array}$ & $\begin{array}{l}\text { Slope } \\
\text { height } \\
{[\mathrm{m}]}\end{array}$ & $\begin{array}{l}\text { Cohesion } \\
\text { kpa }\end{array}$ & $\begin{array}{l}\text { Friction } \\
\text { angle } \\
{\left[{ }^{\circ}\right]}\end{array}$ & $\begin{array}{l}\text { amount of } \\
\text { damage } \\
{\left[\mathrm{g} / \mathrm{m}^{2}\right]}\end{array}$ & $\begin{array}{l}\text { Flood } \\
\text { destruction } \\
\text { Level }\end{array}$ \\
\hline 1 & Heavy rain & 5 & 46 & 11 & 10 & 30 & 125 & 4 \\
\hline 2 & Rainstorm & 3 & 50 & 20 & 18 & 35 & 140 & 5 \\
\hline 3 & Light rain & 2 & 20 & 8 & 5 & 21 & 15 & 1 \\
\hline 4 & Heavy rain & 1 & 38 & 25 & 18 & 31 & 26 & 2 \\
\hline 5 & Light rain & 3 & 47.8 & 26 & 18.8 & 28 & 10 & 1 \\
\hline 6 & Rainstorm & 1 & 48 & 30 & 26 & 5 & 65 & 3 \\
\hline 7 & Moderate rain & 4 & 40 & 31 & 10 & 37.8 & 29 & 2 \\
\hline 8 & Light rain & 11 & 42 & 28 & 35 & 40 & 24 & 2 \\
\hline 9 & Heavy rain & 1 & 33 & 8 & 5 & 40 & 16 & 1 \\
\hline 10 & Moderate rain & 5 & 23 & 18 & 5 & 30 & 17 & 1 \\
\hline 11 & Moderate rain & 3 & 40 & 30 & 45 & 40 & 23 & 2 \\
\hline 12 & Rainstorm & 4 & 45 & 32 & 5 & 26 & 200 & 5 \\
\hline 13 & Rainstorm & 3 & 38 & 13 & 6.6 & 22 & 127 & 4 \\
\hline 14 & Heavy rain & 2 & 46 & 35 & 44 & 36 & 24 & 2 \\
\hline 15 & Heavy rain & 1 & 40 & 28 & 10 & 40 & 16 & 1 \\
\hline NO. & Rainfall grade & Duration & Slope & Slope & $\begin{array}{l}\text { Cohesion } \\
\text { kpa }\end{array}$ & $\begin{array}{l}\text { Friction } \\
\text { angle } \\
{\left[{ }^{\circ}\right]}\end{array}$ & $\begin{array}{l}\text { amount of } \\
\text { damage } \\
{\left[\mathrm{g} / \mathrm{m}^{2}\right]}\end{array}$ & $\begin{array}{l}\text { Flood } \\
\text { destruction } \\
\text { Level }\end{array}$ \\
\hline
\end{tabular}




\begin{tabular}{|c|c|c|c|c|c|c|c|c|}
\hline & & $\begin{array}{l}\text { of rainfall } \\
\text { [day] }\end{array}$ & angle $^{\circ}$ & $\begin{array}{l}\text { height } \\
{[\mathrm{m}]}\end{array}$ & & & & \\
\hline 16 & Heavy rain & 2 & 47 & 25 & 46 & 33 & 28 & 2 \\
\hline 17 & Moderate rain & 7 & 42.2 & 27 & 37.5 & 31 & 22 & 2 \\
\hline 18 & Rainstorm & 2 & 41 & 15 & 16.8 & 27.3 & 26 & 2 \\
\hline 19 & Light rain & 9 & 45 & 26 & 9.6 & 30 & 95 & 4 \\
\hline 20 & Moderate rain & 6 & 41 & 30 & 31.5 & 39.7 & 24 & 2 \\
\hline 21 & Rainstorm & 3 & 46 & 36 & 68 & 36 & 66 & 3 \\
\hline 22 & Light rain & 4 & 34.5 & 28 & 55 & 36 & 6 & 1 \\
\hline 23 & Moderate rain & 9 & 47.1 & 35 & 45 & 35 & 22 & 2 \\
\hline 24 & Heavy rain & 2 & 20 & 10 & 5 & 31 & 26 & 2 \\
\hline 25 & Light rain & 14 & 25 & 6 & 25 & 5 & 67 & 3 \\
\hline 26 & Rainstorm & 1 & 40 & 30 & 16 & 39 & 5 & 1 \\
\hline 27 & Moderate rain & 1 & 35 & 4 & 5 & 30 & 4 & 1 \\
\hline 28 & Light rain & 6 & 30 & 26 & 16 & 30.3 & 8 & 1 \\
\hline 29 & Heavy rain & 2 & 37.8 & 27 & 17.5 & 35 & 22 & 2 \\
\hline 30 & Rainstorm & 1 & 42.6 & 20 & 12 & 33 & 57 & 3 \\
\hline 31 & Rainstorm & 3 & 45 & 23 & 12 & 33 & 28 & 2 \\
\hline 32 & Rainstorm & 1 & 49 & 31 & 68 & 37 & 23 & 2 \\
\hline 33 & Heavy rain & 1 & 33 & 8 & 5 & 40 & 6 & 1 \\
\hline 34 & Light rain & 10 & 50 & 27 & 26 & 31 & 27 & 2 \\
\hline 35 & Rainstorm & 1 & 42.6 & 32 & 37.5 & 36 & 20 & 2 \\
\hline 36 & Heavy rain & 2 & 22.2 & 33 & 40 & 45 & 25 & 2 \\
\hline 37 & Moderate rain & 7 & 36 & 35 & 26 & 25 & 27 & 2 \\
\hline 38 & Rainstorm & 3 & 45 & 20 & 20 & 36 & 112 & 4 \\
\hline 39 & Heavy rain & 7 & 50 & 15.3 & 18.1 & 21.28 & 300 & 5 \\
\hline 40 & Heavy rain & 2 & 40 & 55 & 27.5 & 20 & 24 & 2 \\
\hline
\end{tabular}


samples. In order to ensure the sample data in the same order of magnitude, the neural network input and output data will be normalized. Adopt 3-layer BP neural network, meanwhile the input layer nodes is determined as 6 , the hidden layer nodes of 10 , and the output layer nodes of 1 . Adopt genetic algorithm to optimize BP neural network's initial weight and threshold value, of which population size is 20 , maximum evolution generation of 200 , crossover probability of 0.4 , mutation probability of 0.06 .

Cary out training on GA-BP neural network for 493 times, while the training times of solely adopting BP neural network reach 1460 times. The results show that the flood destruction forecast value and actual value of GA-BP neural network and BP neural network basically reach ideal level. For the latter 5 sets of data serving as the posterior forecast input samples, the comparison results of forecast value and actual value is shown in Table 3.

Table 3. The comparison of flood destruction forecast value and actual value

\begin{tabular}{|c|c|c|c|c|c|}
\hline \multirow[b]{2}{*}{ No. } & \multirow{2}{*}{$\begin{array}{l}\text { Actual } \\
\text { value }\end{array}$} & \multicolumn{2}{|c|}{ GA_BP Network } & \multicolumn{2}{|c|}{ BP Network } \\
\hline & & $\begin{array}{l}\text { Forecast } \\
\text { value }\end{array}$ & Relative error \% & Forecast value & Relative error \% \\
\hline 36 & 25 & 24 & -4 & 26 & 4 \\
\hline 37 & 27 & 26 & -3.7037 & 25 & -7.40741 \\
\hline 38 & 112 & 110 & -1.78571 & 117 & 4.464286 \\
\hline 39 & 300 & 305 & 1.666667 & 290 & -3.33333 \\
\hline 40 & 24 & 26 & 8.333333 & 28 & 16.66667 \\
\hline
\end{tabular}

\subsection{Forecast Structural Analysis}

The forecast results show that the GA-BP neural network model for rural highway flood destruction forecast has more advantages than that of BP neural network model.

First of all, with respect to maximum error $16.67 \%$ of BP neural network flood destruction forecast, GA-BP has smaller relative error, maximum of $8.33 \%$. This shows that the GA-BP neural network model for rural highway flood destruction forecast has higher precision.

Secondly, compared with 1460 training times of BP neural network flood destruction forecast, GA_BP has less training times, and shorter training time is. This shows that the GA-BP neural network model can well solve the disadvantages of slow training speed and easy to fall into local minimum points of BP neural network.

This is because MATLAB will randomly gives network initial weight value and threshold value in every training time of BP neural network, while different weight value and threshold value will produce different training results, with both good and poor training results. Genetic algorithm optimize neural network weight value and threshold value, more stable, more accurate results.

\section{Conclusion}

The application of GA-BP neural network is a new attempt to forecast flood destruction in Western Zhejiang rural highway. Slow training speed and easy to fall into local minimum points of BP neural network restricts the application of the flood destruction forecast. But the genetic algorithm stars search from one population of the possibly potential solution set of the representative issue, with the ability of global optimization. It can optimize the BP neural network structure, initialize weight number and threshold value, so as to improve the accuracy and stability of BP neural network flood destruction forecast results. The forecast results show that the GA-BP neural network model has shorter training time, fast convergence speed and high precision, not easy to fall into local minimum points during learning process. The application of GA-BP neural network to establish flood destruction model and predict flood destruction in Western Zhejiang rural highway is feasible. 


\section{Acknowledgements}

This work was supported by Science and technology project of Quzhou (Item number :2013Y014), and Funding program of Quzhou University (Item number : KY1312)

\section{References}

[1] Zhejiang Highway Administration Bureau,Highway Flood destruction Prevention and Treatment, China Communications Press.,Beijing,2000

[2]Xu Xing, Guo Bingbing, Wang Gongzhong. The Application of artificial neural network in multi water source identification in mine. Journal of Safety Science and Technology., 2016, pp.185 - 181 [3]Cong Shuang. Neural Network Theory And Application of Matlab Toolbox. China Science and Technology Press., Hefei,1998

[4] Peng Song, Fang Zuxiang. Joint optimization of neural network learning algorithm. Journal of Circuits and Systems, 2000 pp. 26-30.

[5] Gao Dongguang. Highway and Flood destruction Bridge Prevention and Treatment, China Communications Press., Beijing, 2002

[6] Liu Haiyue. The Analysis of genetic algorithm and neural network in stock prediction ,master's degree thesis of North Central University .,2011.5

[7] Qiao Weide. The Application of genetic algorithm and neural network in traffic accident prediction. Electric drive automation., 2008,30 (1)pp.41-44

[8] Zhou Ming, Sun Shudong. principle and application of genetic algorithm, National Defense Industry Press., Beijing,1999.6pp.3-15. 